\title{
Microorganisms and antibiotic susceptibilities isolated from urine cultures
}

\author{
Abdullah Gul ${ }^{1}$, Esra Gurbuz ${ }^{2}$ \\ ${ }^{1}$ University of Health Sciences, Bursa Yuksek Ihtisas Training and Research Hospital, Department of Urology, Bursa, Turkey; \\ ${ }^{2}$ Kelkit State Hospital, Department of Infectious Diseases and Clinical Microbiology, Gumushane, Turkey.
}

\begin{abstract}
Summary Objectives: Urinary tract infection (UTI) is the second most common cause of infection among all infectious diseases at hospitals. Antibiogram results are needed to maintain treatment in patients with suspected UTI. However, empirical antibiotic treatment is initiated in patients since it takes time to obtain the results of antibiograms. The aim of this study was to evaluate the urine culture and antibiogram results of patients who were admitted to our hospital with suspected UTI and compare the results with other studies.

Methods: Urine cultures requested from the hospital information system database between January of 2018 and 2019 were analyzed. Microorganism-positive urine samples and antibiogram results were evaluated and included in the study. Results: Of the patients, $748(61.8 \%)$ were female and 463 (38.2\%) were male. The average age of all patients was 44.9 years. Escherichia coli was the most frequently isolated microorganisms from urine cultures $(n=828,68.4 \%)$. Among all microorganism-positive urine samples, antibiotic resistance against Cefalexin, Fusidic acid, Ampicillin, Erythromycin, Levofloxacin, Cefuroxime Axetil, Trimethoprim/ Sulfamethoxazole, Ceftriaxone and Ciprofloxacin was $83.9 \%$, $68.4 \%, 61.8 \%, 44.7 \%, 42.7 \%, 36.4 \%, 30 \%, 28.6 \%$ and $26.7 \%$, respectively.

Conclusions: High resistance to Cefalexin, Ampicillin,

Cefuroxime, Axetil, Trimethoprim/ Sulfamethoxazole, Ceftriaxone and Ciprofloxacin, which are often preferred in empirical antibiotic selection, has been found. We believe that empirical antibiotic selection should not be overlooked in cases of UTI. Our study may help clinicians use appropriate antibiotics for the clinical management of UTIs.
\end{abstract}

KEY WORDS: Antibiotic resistance; Microorganisms; Urine culture.

Submitted 18 November 2019; Accepted 19 January 2020

\section{INTRODUCTION}

Antibiotic-resistant microorganisms are becoming widespread and the emergence of bacteria causing multidrugresistant (MDR) urinary tract infection (UTI) has become a major public health problem $(1,2)$. UTIs are the second most common cause of infection among all infectious diseases at hospitals (3). Around 150 million new UTI cases develop worldwide each year, with an estimated treatment cost of $\$ 150$ billion (4). The urethra is a portal for urine output, but it also allows pathogenic microorganisms to enter the urinary tract. Bacteria live in the vicinity of the urethral opening in both men and women and routinely colonize urine, but women are more likely to develop UTIs resulting from anatomical differences, hormonal effects and behavior $(5,6)$. Antibiograms are used to maintain treatment in patients with suspected UTIs. However, empirical antibiotic treatment is initiated in patients since it takes time to obtain the results of antibiograms. The causative agent and the selected antibiotic affect the success of the treatment. The choice of drug for empirical antibiotic treatment is very important because of antibiotic resistance. Empirical antibiotic selection should be followed at regular intervals for the sensitivity results of the hospital and the region studied (7). Because the prevalence of UTI pathogens and their resistance to different antibiotics may have changed over the years (8). Antimicrobial resistance is increasing worldwide, leading to infections that are difficult to treat and are associated with high mortality, morbidity and cost $(9,10)$.

The aim of this study was to evaluate the urine culture and antibiogram results of patients who were admitted to our hospital with suspected UTI and compare the results with other studies. We believe that our study will help physicians select appropriate empirical antibiotics for the clinical management of UTIs. Morever, it may serve as data source for reviews and meta-analysis in future.

\section{MATERIALS AND METHODS}

In this study, both urine cultures and antibiogram results of 1211 patients who were admitted to urology outpatients clinic of Van Regional Training and Research Hospital between 2018-2019 and who were positive for urine culture were analyzed retrospectively. In the microbiology laboratory urine samples obtained for culture from mid stream by sterile urine containers were evaluated as standard with 0.01 milliliter calibrated flasks with 5\% sheep blood and eosin methylene blue (EMB) agar and incubated at $37^{\circ} \mathrm{C}$ for $18-24$ hours. Isolated bacteria were identified by fully automated identification with antibiogram device (VITEK 2 Compact BioMerieux, France) and antibiotic susceptibility results were determined. Antibiogram results were given in three groups as less sensitive, sensitive and resistant. Data were expressed as mean \pm standard deviation and percentage.

\section{RESULTS}

Of the patients, 748 (61.8\%) were female and 463 (38.2\%) were male. The average age of all patients was 44.9 years. 
It was 38.2 years in female patients whilst 55.8 years in male patients. Escherichia coli (E. coli) was the most frequently isolated microorganisms $(n=828,68.4 \%)$ from urine cultures. Isolated microorganisms are shown in Table 1 as number and percentage.

When all samples were examined, antibiotic resistance against to Cefalexin, Fusidic acid, Ampicillin, Erythromycin, Netilmicin, Levofloxacin was 83.9\%, 68.4\%, 61.8\%, 44.7\%, $43.8 \%, 42.7 \%$, respectively.

Also, antibiotic resistance to Cefuroxime Axetil, Cefuroxime, Cefixime, Trimethoprim/Sulfamethoxazole, Ceftriaxone,

Table 1.

Microorganisms isolated from urine cultures.

\begin{tabular}{|c|c|c|}
\hline Isolated microorganisms & Number & Percent (\%) \\
\hline Acinetobacter spp & 2 & 0.17 \\
\hline Acinetobacter baumannii & 7 & 0.58 \\
\hline Alcaligenes faecalis & 1 & 0.08 \\
\hline Burkholderia cepacia & 1 & 0.08 \\
\hline Candida albicans & 15 & 1.24 \\
\hline Candida famata & 1 & 0.08 \\
\hline Candida kefyr & 2 & 0.17 \\
\hline Candida krusei & 1 & 0.08 \\
\hline Candida spherica & 3 & 0.25 \\
\hline Candida tropicalis & 3 & 0.25 \\
\hline Citrobacter freundii & 2 & 0.17 \\
\hline Citrobacter koseri & 3 & 0.25 \\
\hline Enterobacter aerogenes & 1 & 0.08 \\
\hline Enterobacter cloacae complex & 9 & 0.74 \\
\hline Enterococcus spp & 4 & 0.33 \\
\hline Enterococcus faecalis & 55 & 4.5 \\
\hline Enterococcus faecium & 9 & 0.74 \\
\hline Escherichia coli & 828 & 68.4 \\
\hline Klebsiella spp & 34 & 2.8 \\
\hline Klebsiella oxytoca & 6 & 0.5 \\
\hline Klebsiella pneumoniae & 87 & 7.2 \\
\hline Morganella morganii & 3 & 0.25 \\
\hline Proteus spp. & 4 & 0.33 \\
\hline Proteus mirabilis & 21 & 1.73 \\
\hline Providencia rettgeri & 4 & 0.33 \\
\hline Pseudomonas aeruginosa & 24 & 1.2 \\
\hline Salmonella spp & 1 & 0.08 \\
\hline Serratia fonticola & 2 & 0.17 \\
\hline Serratia liquefaciens group & 2 & 0.17 \\
\hline Serratia marcescens & 1 & 0.08 \\
\hline Shigella sonnei & 1 & 0.08 \\
\hline Staphylococcus aureus & 4 & 0.33 \\
\hline Staphylococcus epidermidis & 23 & 1.9 \\
\hline Staphylococcus haemolyticus & 3 & 0.25 \\
\hline Staphylococcus hominis & 1 & 0.08 \\
\hline Staphylococcus saprophyticus & 6 & 0.5 \\
\hline Staphylococcus warneri & 1 & 0.08 \\
\hline Stteptococcus spp & 2 & 0.17 \\
\hline Streptococcus agalactiae & 26 & 2.15 \\
\hline Streptococcus constellatus ssp pharyngis & 1 & 0.08 \\
\hline Streptococcus dysgalactiae ssp equisimilis & 2 & 0.17 \\
\hline Streptococcus mitis & 3 & 0.25 \\
\hline Streptococcus salivarius ssp salivarius & 1 & 0.08 \\
\hline Streptococcus sanguinis & 1 & 0.08 \\
\hline$\overline{\text { Total }}$ & 1211 & 100 \\
\hline
\end{tabular}

Ciprofloxacin was found to be $36.4 \%, 36 \%, 34.3 \%, 30 \%$, $28.6 \%$ and $26.7 \%$, respectively. No microorganisms were found to be resistant to Amphotericin B. Chloramphenicol, Colistin, Flucytosine and Rifampicin. However, antibiotic resistance to Meropenem, Ertapenem, Imipenem and Amikacin was found to be $0.88 \%, 1.14 \%, 1.5 \%$ and $1.6 \%$, respectively. The data on the resistance status of antibiotics are given in Table 2 as number and percentage.

Table 2.

Antibiotic resistance rates.

\begin{tabular}{|c|c|c|c|c|c|}
\hline Antibiotic & Sensitive & $\begin{array}{c}\text { Low } \\
\text { sensitive }\end{array}$ & Resistant & Total & $\begin{array}{c}\text { Percent } \\
(\%)\end{array}$ \\
\hline Amikacin & 719 & 178 & 15 & 912 & 1.6 \\
\hline Amoxicillin/Clavulanic Acid & 13 & 1 & 7 & 21 & 33.3 \\
\hline Amphotericin B & 15 & 0 & 0 & 15 & 0 \\
\hline Ampicillin & 362 & 2 & 588 & 952 & 61.8 \\
\hline Ampicillin/Sulbactam & 69 & 0 & 15 & 84 & 17.9 \\
\hline Aztreonam & 5 & 18 & 4 & 27 & 14.8 \\
\hline Benzylpenicillin & 29 & 5 & 3 & 37 & 8.1 \\
\hline Caspofungin & 17 & 0 & 1 & 15 & 5.6 \\
\hline Cefalexin & 5 & 0 & 26 & 31 & 83.9 \\
\hline Cefepime & 25 & 1 & 3 & 29 & 10.3 \\
\hline Cefixime & 574 & 0 & 300 & 874 & 34.3 \\
\hline Cefotaxime & 14 & 0 & 1 & 5 & 6.7 \\
\hline Cefoxitin & 24 & 769 & 82 & 875 & 9.4 \\
\hline Ceftazidime & 625 & 68 & 218 & 911 & 23.9 \\
\hline Ceftriaxone & 609 & 26 & 254 & 889 & 28.6 \\
\hline Cefuroxime & 561 & 0 & 316 & 877 & 36 \\
\hline Cefuroxime Axetil & 557 & 0 & 319 & 876 & 36.4 \\
\hline Chloramphenicol & 4 & 0 & 0 & 4 & 0 \\
\hline Ciprofloxacin & 698 & 46 & 271 & 1015 & 26.7 \\
\hline Clindamycin & 35 & 0 & 10 & 45 & 22.2 \\
\hline Colistin & 37 & 0 & 0 & 37 & 0 \\
\hline Daptomycin & 53 & 0 & 3 & 56 & 5.4 \\
\hline Ertapenem & 865 & 2 & 10 & 877 & 1.14 \\
\hline Erythromycin & 21 & 0 & 17 & 38 & 44.7 \\
\hline Fluconazole & 17 & 0 & 1 & 18 & 5.6 \\
\hline Flucytosine & 17 & 1 & 18 & 36 & 0 \\
\hline Fosfomycin & 847 & 0 & 59 & 906 & 6.5 \\
\hline Fusidic Acid & 12 & 0 & 26 & 38 & 68.4 \\
\hline Gentamicin & 835 & 5 & 111 & 951 & 11.7 \\
\hline Imipenem & 873 & 24 & 14 & 911 & 1.5 \\
\hline Levofloxacin & 46 & 1 & 35 & 82 & 42.7 \\
\hline Linezolid & 130 & 0 & 2 & 132 & 1.5 \\
\hline Meropenem & 891 & 14 & 8 & 913 & 0.88 \\
\hline Micafungin & 17 & 0 & 1 & 18 & 5.6 \\
\hline Moxifloxacin & 17 & 0 & 4 & 21 & 19 \\
\hline Netilmicin & 18 & 0 & 14 & 32 & 43.8 \\
\hline Nitrofurantoin & 798 & 1 & 75 & 874 & 8.6 \\
\hline Oxacillin & 23 & 0 & 15 & 38 & 39.5 \\
\hline Piperacillin & 15 & 2 & 10 & 27 & 37 \\
\hline Piperacillin/Tazobactam & 682 & 96 & 124 & 902 & 13.7 \\
\hline Rifampicin & 0 & 4 & 0 & 4 & 0 \\
\hline Teicoplanin & 92 & 0 & 8 & 100 & 8 \\
\hline Tetracycline & 28 & 0 & 13 & 41 & 31.7 \\
\hline Tigecycline & 113 & 4 & 0 & 117 & 0 \\
\hline Tobramycin & 26 & 0 & 16 & 42 & 18.8 \\
\hline Trimethoprim/Sulfamethoxazole & 677 & 35 & 310 & 1022 & 30.3 \\
\hline Vancomycin & 128 & 0 & 4 & 132 & 3 \\
\hline Vorikonazol & 16 & 0 & 0 & 16 & 0 \\
\hline
\end{tabular}




\section{Discussion}

Bacteria are the most common etiology of UTIs, accounting for more than $95 \%$ of cases. E. coli is the most common causal organism of UTIs and is responsible for more than $80 \%$ of them (11). Wright et al. reported that the rate of E. coli in urine cultures was 67\% (12). Another study conducted by Akbas et al. revealed that the rate of $E$. coli in urine cultures was $35-80 \%$ (13). In our study, we found the rate of E. coli to be $68.4 \%$ and this rate is consistent with other studies. Microorganisms and antibiotic susceptibilities isolated from urine cultures may differ among countries due to usage of different agents and multifactorial causes. In our study, a serious resistance to Cefalexin, which is one of the most common antibiotics used for the treatment of UTIs, is observed. In a study published in 2019, Shrestha et al. reported a 60\% resistance to Cefalexin (14). Ganesh and colleagues also reported 94.1\% resistance to Cefalexin in their study in the same year (15). In our study, antibiotic resistance rate to Cefalexin was found to be $83.9 \%$. All three studies point out that the rate of antibiotic resistance to Cefalexin is high. Zhanel et al. reported a resistance rate of Ampicillin to 37.7\% in 2006 (16). Bryce et al. found the resistance rate to Ampicillin as $60.3 \%$ in 2016 (17). In our study, the resistance rate to Ampicillin was found to be $61.8 \%$. Antibiotics prescribed for UTIs, most of which are caused by E. coli, have a high prevalence of resistance. When we look at the studies conducted worldwide, we found that Ampicillin resistance rate is the highest and Nitrofurantoin resistance rate is at very low levels. In our study, we found the Nitrofurantoin resistance rate to be $8.6 \%$.

\section{Conclusions}

Empirical antibiotic selection against E. coli, which is the most frequently isolated microorganism in urine cultures of patients with suspected UTI, was highly resistant to most of the antibiotics that are frequently preferred. We think that empirical antibiotic selection in cases of UTI should not be overlooked and that such studies should be repeated frequently to carry out current antibiotic susceptibilities.

\section{References}

1. Ibrahim ME, Bilal NE, Hamid ME. Increased multi-drug resistant Escherichia coli from hospitals in Khartoum state, Sudan. Afr Health Sci. 2012; 12:368.

2. Tiruneh M, Yifru S, Gizachew M, et al. Changing trends in prevalence and antibiotics resistance of uropathogens in patients attending the Gondar University Hospital, Northwest Ethiopia. Int J Bacteriol. $2014 ; 2014: 629424$

3. Saraçoglu KT, Fidan V, Pekel Ö, et al. İdrar kültürlerinde izole edilen bakterilerin antibiyotik duyarlilılan. J of Clin and Exp Inv. 2013; 4:356.

4. Kadanalı A. Üriner sistem infeksiyonlan. Eurasian J Med. 2006; 38:119.

5. Foxman, B. The epidemiology of urinary tract infection. Nat Rev Urol. 2010; 7:653.

6. Minardi $D$, d'Anzeo $G$, Cantoro D, et al. Urinary tract infections in women: etiology and treatment options. Int J Gen Med. 2011; 4:333.
7. Sucu N, Aktoz-Boz G, Bayraktar Ö, et al. Üropatojen Escherichia coli suslarının antibiyotik duyarlılıklarının yıllar içerisindeki degisimi. Klimik Dergisi. 2004; 17:128.

8. Kehinde A, Adedapo K, Aimakhu C, et al. Urinary pathogens and drug susceptibility patterns of urinary tract infections among antenatal clinic attendees in Ibadan, Nigeria. J Obstet Gynaecol Res. 2012; 38:280.

9. Gardiner BJ, Stewardson AJ, Abbott IJ, Peleg AY. Nitrofurantoin and fosfomycin for resistant urinary tract infections: old drugs for emerging problems. Aust Prescr. 2019; 42:14.

10. Perletti G, Magri V, Cai T, et al. Resistance of uropathogens to antibacterial agents: Emerging threats, trends and treatments. Arch Ital Urol Androl. 2018; 90:85.

11. Nachimuthu R, Chettipalayam S, Velramar B, et al. Urinary tract infection and antimicrobial susceptibility pattern of extended spectrum beta lactamase producing clinical isolates. Adv Biol Res. 2008; $2: 78$.

12. Wright SW, Wrenn KD, Haynes ML. Trimethoprim-sulfamethoxazole resistance among urinary coliform isolates. Int J Gen Med. 1999; 14:606.

13. Akbas E, Zarakolu P, Aktepe OC, et al. İdrar yolu enfeksiyonu ön tanısı ile basvuran olgularda idrar örneklerinin mikrobiyolojik olarak degerlendirilmesi: İki yıllık bir çalısma. Mikrobiyoloji Bülteni. 1997; 31:351.

14. Shrestha LB, Baral R, Poudel P, Khanal B. Clinical, etiological and antimicrobial susceptibility profile of pediatric urinary tract infections in a tertiary care hospital of Nepal. BMC Pediatr. 2019; 19:36.

15. Ganesh R, Shrestha D, Bhattachan B, Rai G. Epidemiology of urinary tract infection and antimicrobial resistance in a pediatric hospital in Nepal. BMC Infect Dis. 2019; 19:420.

16. Zhanel GG, Hisanaga TL, Laing NM, et al. Antibiotic resistance in Escherichia coli outpatient urinary isolates: final results from the North American Urinary Tract Infection Collaborative Alliance (NAUTICA). Int J Antimicrob Agents. 2006; 27:468.

17. Bryce A, Hay AD, Lane IF, et al. Global prevalence of antibiotic resistance in paediatric urinary tract infections caused by Escherichia coli and association with routine use of antibiotics in primary care: systematic review and meta-analysis. BMJ. 2016; 352; 1939.

\author{
Correspondence \\ Abdullah Gul, MD \\ dr_abdullahgul@hotmail.com \\ Bursa Training and Research Hospital \\ Floor 2, 16310 Bursa (Turkey) \\ ORCID 0000-0003-4002-4659 \\ Esra Gurbuz, MD \\ dr.inanhazan@gmail.com \\ Kelkit State Hospital, Department of Infectious Diseases \\ and Clinical Microbiology, Gumushane (Turkey)
}

